УДК 327(55)

ББК 63.3(5) (Ирн)

\title{
Реакция Исламской Республики Иран на выход США из Совместного всеобъемлющего плана действий
}

\author{
В.П. Румянцев, А.ШІ. Хакимов \\ Национальный исследовательский Томский государственный университет \\ (Томск, Россия)

\section{The Response of the Islamic Republic of Iran to the US Withdrawal from the Joint Comprehensive Plan of Action}

\author{
V.P. Rumyantsev, A.Sh. Khakimov \\ National Research Tomsk State University (Tomsk, Russia)
}

В мае 2018 г. президент США Д. Трамп заявил о выходе Соединенных Штатов из Совместного всеобъемлющего плана действий, принятого в 2015 г. для решения иранской ядерной проблемы. В данной статье анализируется то, как на этот шаг прореагировало руководство Ирана, его население, и каковы перспективы достижения целей, которые ставил перед собой официальный Вашингтон. Помимо внутриполитических соображений и укрепления союзнических отношений с Израилем и Саудовской Аравией, Д. Трамп рассчитывал, что его инициатива как минимум приведет к изменению внешней политики Ирана, а как максимум - к смене власти в Тегеране в результате недовольства населения своим бедственным положением. Очевидно, что американское руководство просчиталось. Экономическая ситуация в Иране действительно ухудшилась, но все основные направления внешней политики исламской республики остались в силе, при этом Иран стал наращивать свое сотрудничество с Сирией, Россий и Китаем. Усилилась и антиизраильская риторика официальных иранских властей. Новые экономические санкции со стороны США привели к росту антиамериканских настроений, вместо того чтобы подстегнуть антиправительственные выступления. Таким образом, в очередной раз в своей истории в случае внешнего давления иранцы сплачиваются вокруг своего руководства.

Ключевые слова: Исламская Республика Иран, Соединенные Штаты Америки, Совместный всеобъемлющий план действий, Дональд Трамп, Хасан Рухани.
In May 2018, U.S. President Donald Trump announced withdrawal of the United States from the Joint Comprehensive Plan of Action adopted in 2015 for solution of the Iran nuclear deal. This article analyzes how Iran's leaders and population reacted to this step and what the prospects for achieving the goals of official Washington are. In addition to domestic political considerations and the strengthening of allied relations with Israel and Saudi Arabia, President Trump hoped that his initiative would at least lead to a change in Iran's foreign policy, and as a maximum to a change of power in Tehran as a result of the people's dissatisfaction with the economic plight. Obviously, the American leaders miscalculated with the last two points. The economic situation in Iran has really worsened, but all the main directions of the foreign policy of the Islamic republic not only remained in force, but Iran began to increase its cooperation with Syria, Russia and China. The antiIsraeli rhetoric of official Iranian authorities has also intensified. New US economic sanctions have led to an increase in anti-American sentiment instead of spurring anti-government protests. Thus, once again in the history of Iran the Iranians rally around their government in the event of external pressure.

Key words: Islamic Republic of Iran, United States, Joint Comprehensive Plan of Action, Donald Trump, Hasan Rouhani.

DOI 10.14258/izvasu(2019)6-15 
Проблема нераспространения ядерного оружия является одной из ключевых в современной мировой повестке дня. Одним из наиболее острых аспектов этой проблемы можно считать ядерную программу Ирана. В 2015 г. Иран и страны «шестерки» (США, Франция, Великобритания, Германия, Китай и Россия) подписали Совместный всеобъемлющий план действий (СВПД) по иранской ядерной программе. По этому соглашению Иран должен допустить инспекторов Международного агентства по атомной энергии на свои ядерные объекты, а страны Запада, в свою очередь, должны были постепенно отменять возложенные на Иран санкции. 8 мая 2018 г. президент США Д. Трамп объявил о выходе страны из иранской ядерной сделки. Этот односторонний шаг вызвал немало комментариев в публицистической и научной литературе. И хотя недостатка в суждениях нет, почти все они сосредоточены на анализе причин, подтолкнувших Белый дом к подобному шагу [1-7]. При этом мало внимания уделяется самому Ирану, его реакции на выход США из СВПД и возможным последствиям этого акта для политики исламской республики. Заполнить отчасти данный пробел - цель написания данной статьи.

В 2013 г. новым президентом Ирана стал Хасан Рухани. Он сразу же обозначил свое намерение проводить более взвешенный курс, чем его предшественник М. Ахмадинежад. Подтверждением его намерений стало данное им обещание об изменениях в подходе к ядерной программе страны. Х. Рухани подверг жесткой критике непрофессиональную, «агрессивную» политику М. Ахмадинежада. Он считал, что его предшественник слишком поздно понял отрицательный эффект экономических санкций. Рухани призывал к прямым переговорам с США. «Старые раны необходимо залечить», подчеркивал Х. Рухани, выступая на своей первой пресс-конференции после избрания. Показательно, что высший руководитель Ирана, его духовный лидер А. Хаменеи впервые за четверть века в должности рахбара заявил, что не будет препятствовать началу таких переговоров [8, с. 59].

Следующим примирительным шагом Х. Рухани стало выступление 26 сентября 2013 г. на конференции ООН по разоружению, где он призвал избавить мир от ядерного оружия. «Вместо ядерного оружия давайте инвестируем в искоренение нищеты, невежества, болезней и в развитие», - предложил он [9]. На следующий день, 27 сентября, президент США Б. Обама сообщил, что у него состоялся телефонный разговор с Х. Рухани. «Мы обсудили наши текущие усилия по достижению соглашения по ядерной программе Ирана», - сказал Обама на брифинге в Белом доме [10]. Этот разговор был первой прямой коммуникацией между американским и иранским президентами после Исламской революции 1979 г.
Таким образом, после многих лет политического давления и санкций США были готовы вести диалог с Ираном. Результатом этой готовности и стало заключение СВПД, переговоры о котором длились без малого 12 лет. На первый взгляд казалось, что после заключения СВПД отношения Тегерана и Вашингтона потеплели. Из них начала исчезать воинственная риторика. Иран получил 1,7 млрд долл. в результате урегулирования части взаимных исков [11, с. 237].

Но с приходом Д. Трампа на пост президента США в январе 2017 г. американская политика по отношению к Ирану стала меняться. Изменения стали заметны еще в стадии предвыборной кампании. Д. Трамп, критикуя СВПД, заявлял, что это была «худшая сделка в истории», ставшая «катастрофой для Израиля, Америки и для всего Ближнего Востока», и в случае его избрания «приоритетом № 1 будет ее аннулирование» [11, с. 238-239].

Став президентом, Д. Трамп оказался верен своим обещаниям. В октябре 2017 г. он, обвинив Иран в содействии терроризму и оказании помощи «АльКаиде» (деятельность запрещена на территории России), «Талибану», «Хезболле», «ХАМАСу» в разработке и распространении ракет, угрожающих американским войскам и их союзникам, заявил: «Вопервых, мы будем работать с нашими союзниками над противодействием дестабилизирующей деятельности режима и поддержкой террористов в регионе. Во-вторых, мы введем дополнительные санкции в отношении режима, чтобы блокировать его финансирование террора. В-третьих, мы займемся борьбой с распространением ракет и оружия, угрожающих соседям режима, глобальной торговлей и свободой судоходства. И, наконец, мы откажем режиму во всех путях к ядерному оружию» [12].

$\mathrm{X}$. Рухани прокомментировал данную речь, предложив президенту Америки обратиться к истории, вспомнив некоторые ее моменты: «В словах господина Трампа о политике Ирана не было ничего, кроме оскорблений и нагромождения ложных обвинений в адрес иранского народа. Я приглашаю президента США подробнее ознакомиться с историей, географией, международными обязательствами, вежливостью и этикой, международными конвенциями. По-видимому, он не знает, что правительство США устроило переворот шестьдесят с лишним лет назад, и это была сила, которая свергла верховенство закона, зарабатывая деньги и используя своих наемников. По-видимому, он забыл, что во время интегрированной кампании иранского народа против диктатуры с целью завоевания свободы, независимости и Исламской Республики на этой земле именно Соединенные Штаты в значительной степени поддерживали диктатора в Иране» [13].

Президент Ирана использовал характерный для многих ближневосточных политиков прием, ссылаясь 
на участие американских спецслужб в свержении правительства М. Моссадыка в Тегеране в 1953 г. и последующую безоговорочную американскую поддержку шаха М.Р. Пехлеви, которая способствовала уничтожению политической оппозиции шахскому режиму [14, с. 97-116].

12 января 2018 г. Д. Трамп предупредил, что откажется от ядерной сделки с Ираном, если европейские партнеры не согласятся исправить допущенные недостатки в соглашении. В тот же день Министерство финансов США поместило в список лиц, в адрес которых действуют ограничительные санкции, 14 иранских государственных деятелей, включая начальника судебной системы Ирана, за нарушения прав человека и поддержку распространения оружия [15].

Свои обещания президент США сдержал. 8 мая 2018 г. он подписал меморандум о выходе США от СВПД и введении новых экономических санкций. «Мы введем экономические санкции самого высокого уровня. Любая страна, которая помогает Ирану в его стремлении получить ядерное оружие, также может быть подвергнута сильным санкциям со стороны Соединенных Штатов», - заверил американский лидер [16].

За решением Белого дома скрывалось несколько соображений. Прежде всего Д. Трампу необходимо было укрепить собственные позиции внутри Республиканской партии, доказав, что он является лидером, чьи слова не расходятся с делом. Кроме того, инициатива Вашингтона имела целью укрепление отношений с ключевыми союзниками США в регионе Израилем и Саудовской Аравией. Нового здесь было мало. В свое время интерес США к Ирану точно охарактеризовали слова государственного секретаря Корделла Хэлла: «В наших интересах, чтобы в Персидском заливе не укрепилось противоречащее позициям нефтяных американских компаний в Саудовской Аравии влияние какой-либо великой державы» [17, с. 161]. Вместе с тем выход из СВПД имел заявленную и незаявленную цели. К заявленной цели можно отнести, как уверяет исследовательская служба американского конгресса, оказание «максимального экономического давления на Иран с тем, чтобы вынудить его изменить свое поведение по различным вопросам, представляющим интерес для США, включая поддержку Ираном вооруженных группировок в регионе». Но есть не декларируемая цель. Она заключается в смене власти в Тегеране. Соединенные Штаты явно рассчитывали на протестные настроения в Иране, которые в перспективе могут все больше приобретать политический характер. Этому, в частности, должен способствовать созданный в 2018 г. Соединенными Штатами новый круглосуточный телеканал, вещающий на персидском языке [4, с. 31-32].

Расчеты американского руководства могли строиться на значительном росте антиправительствен- ных настроений в конце 2017 г. - начале 2018 г., вызванного недовольством высоким уровнем коррупции, экономическими проблемами и нежеланием исламского духовенства реформировать иранское общество. Волна протестов, охватившая крупнейшие иранские города, сошла на нет к середине января 2018 г.

Реакция иранских политиков на заявление Д. Трампа варьировалась от яростно негодующей до сдержанной. Наибольшее негодование ожидаемо исходило от консервативных кругов иранского общества. Аятолла Хоменеи заявил на следующий день после демарша Д. Трампа: «Мы давно говорили, что нельзя доверять США, и вот результат! ... Наши чиновники и властные структуры говорят мне, что они хотят продолжить сотрудничать в рамках СВПД с этими тремя европейскими странами [Францией, Германией и Великобританией. B.P., A.X.]. Я же не доверяю и им тоже» [18]. В тот же день консервативные члены иранского парламента сожгли на крыльце меджлиса копию текста о СВПД под одобрительные крики толпы: «Смерть Америке!». Американские флаги были сожжены и перед зданием бывшего посольства США в Тегеране [19]. Председатель Меджлиса исламского совета Ирана А. Лариджани назвал слова Трампа «опрометчивыми и дешевыми», добавив, что президент США более года выступал с «дипломатическим шоу. Похоже, что у господина Трампа нет умственной способности решать проблемы, и язык силы подходит лучше для того, чтобы иметь дело с этим человеком, чтобы он мог осознать последствия своего высокомерия» [20].

Весьма показательной была реакция силовых структур Ирана. Начальник штаба Вооруженных сил Ирана генерал-майор М. Багери заявил, что Соединенные Штаты решили прибегнуть к «экономической войне», убедившись, что не смогут осуществить вооруженное вторжение в исламскую республику. «СВПД не являлся оптимальным выбором для нашей нации и чем-то, что мы обязаны были принять, но мы приняли его ради сохранения мира. Однако эта высокомерная держава даже не оказалась верной своей подписи», - подчеркнул Багери. Командующий иранской армией генерал-майор А. Мусави добавил, что он даже рад, что США вышли из исторического ядерного соглашения 2015 г., доказав всем, что Вашингтон - ненадежный партнер, которому нельзя доверять [20].

Реакцию самого Х. Рухани можно охарактеризовать как сдержанно-ироничную. Президент ИРИ заявил, что Соединенные Штаты «подтвердили, что не собираются выполнять собственные обещания». Сам же Рухани пообещал пока соблюдать соглашение и поручил своим дипломатам провести переговоры с остальными сторонами, подписавшими 
соглашение, заявив, что соглашение может существовать и без Соединенных Штатов [21].

Если власти США и рассчитывали, что их выход из СВПД ударит по позициям Х. Рухани и заставит Иран быть более сговорчивым, то они добились совершенно обратного эффекта. Как свидетельствует бывший член делегации Ирана на переговорах по ядерной сделке С.Х. Мусавян, ныне работающий в Принстонском университете, экономическая ситуация в Иране значительно ухудшилась, но простые иранцы в этом обвиняют не свое правительство, а Соединенные Штаты. И чем жестче становится санкционный режим, тем больше иранцы сплачиваются вокруг своего руководства [22]. Х. Рухани побеждал на выборах 2013 и 2017 гг. во многом благодаря поддержке молодежи и сторонников реформ. Они ждали экономического подъема и открытости Ирана после подписания СВПД. Новые санкции подорвали их веру в то, что Запад способен держать данное им слово.

Показательно, что антиправительственные выступления явно пошли на спад. В начале августа 2018 г. протесты прошли в Тегеране, Ширазе, Кередже и Куме. Недовольство иранцев вызвало ухудшение уровня жизни вследствие подорожания цен на товары первой необходимости и инфляции. Но масштабы выступлений были явно несопоставимы с подобными акциями конца 2017 г. - начала 2018 г. В антиправительственных митингах приняли участие всего несколько сотен человек [23].

4 ноября 2018 г. тысячи иранцев вышли на улицы своих городов, чтобы принять участие в мероприятиях, приуроченных к Национальному дню борьбы с мировым империализмом. А. Лариджани сказал, что иранский народ во время массовых демонстраций 4 ноября покажет, что президент США Дональд Трамп слишком мал, чтобы поставить на колени иранский народ [24].

Не оправдались надежды на изменение внешнеполитического курса Тегерана. В частности, президент Х. Рухани заметно усилил свою антиизраильскую риторику. В ноябре 2018 г. на 32-й Международной конференции Исламского единства в Тегеране он заявил, что Израиль является фальшивым режимом, созданным западными странами. Президент ИРИ резко заметил: «Одним из фатальных последствий Второй мировой войны было образование этой раковой опухоли в регионе». Он также заявил, что «различие между исламским миром и Соединенными Штатами состоит в свободе и рабстве, и мусульмане должны в полную силу противостоять американским издевательствам над народами» [25]. Примечательно, что эти слова прозвучали из уст человека, с которым в свое время связывались надежды на нормализацию израильско-иранских отношений и который в своем микроблоге в Твиттере в 2013 г. пожелал всем ев- реям счастливого Рош ха-Шана (еврейского нового года) [26], что было воспринято как сигнал об изменении антиизраильского курса Тегерана.

Очередным актом американского давления на Иран стало признание в апреле 2019 г. Корпуса стражей исламской революции (КСИР) международной террористической организацией. Госсекретарь США М. Помпео заявил, что этот шаг призван «помочь жителям Ирана вернуть свою свободу» [27]. Очевидно, что последствия этого акта не вполне осознавались в Белом доме. С.Х. Мусавян отмечал в этой связи, что с 1980 по 1988 г. члены многих иранских семей добровольно вступили в КСИР, чтобы защитить свою страну от агрессии Саддама Хусейна. «Среди этих молодых людей высоко ценятся мученики, чьи портреты написаны на фресках во всех иранских городах. Многие из них - ветераны с увечьями. Мой собственный брат и двое двоюродных братьев погибли, защищая территориальную целостность Ирана в этой войне», - заметил иранский эксперт в области ядерного нераспространения. Он привел в качестве свидетельства возросшего антиамериканизма иранцев сцену, свидетелем которой он был лично, когда уличная толпа радовалась сбитому КСИР американскому беспилотнику над Ормузским проливом [22]. После решения Д. Трампа общественная поддержка возглавляющего КСИР генерал-майора М.А. Джафари в самом Иране только возросла. Сейчас он является одним из самых популярных деятелей страны.

Сложно сказать - действительно ли в Белом доме верят в возможность новой революции в Иране, которая сместит антиамериканский режим, на место которого придут дружественные США политические силы. Возможно, следует согласиться с известным российским экспертом, генеральным директором Российского совета по международным делам А.В. Кортуновым, который считает, что подобные расчеты Белого дома опираются на мнения и прогнозы проживающих в США иранских политических диссидентов, которым нравится считать нынешний режим весьма слабым и хрупким и верить, что усиление давления США ускорит его неизбежный крах [7].

Таким образом, если целью выхода США из СВПД было спровоцировать очередной международный кризис вокруг ядерной программы Ирана, то эта цель достигнута. Но то, насколько ухудшение экономической ситуации в исламской республике способно привести к изменению политического климата в стране, остается спорным вопросом. И дело даже не в эффективном пропагандистском воздействии иранских властей на собственное население. История неоднократно доказывала, что в моменты внешнего давления иранцы склонны сплачиваться вокруг своего руководства, нежели обвинять его во всех своих проблемах. 


\section{Библиографический список}

1. McCarthy A. Trump Dumps Iran Deal - Hallelujah! // National Review. May 8, 2018. URL: https://www.nationalreview. com/2018/05/president-trump-exits-iran-deal-boost-for-globalsecurity/ (дата обращения: 01.08.2019).

2. Gilmour D. Trump's Reneging on Iran Deal Has Enthused His Supporters // The Daily Dot. May 8, 2018. URL: https:// www.dailydot.com/layer8/conservatives-praise-trumpswithdrawal-from-iran-deal (дата обращения: 01.08.2019).

3. Okun E. Obama: Withdrawing from Iran Nuclear Deal 'Is a Serious Mistake' // Politico. May 8, 2018. URL: https:// www.politico.com/story/2018/05/08/obama-iran-nucleardeal-trump-574610 (дата обращения: 01.08.2019).

4. Косарев В.А., Виловатых А.В., Глазова А.В., Михайлова С.А., Алхименков М.А., Кравченко И.Ю. Политика администрации Д. Трампа на Ближнем Востоке как отражение лозунга «Америка прежде всего» // Проблемы национальной стратегии. 2019. № 2 (53).

5. Ханалиев Н.У. Треугольник «Россия - Турция Иран» в контексте стратегии США на Ближнем Востоке // Вестник РУДН. Серия: Политология. 2019. Т. 21, №1.

6. McKernan B. Iran Nuclear Deal: Why Has Trump Withdrawn US From It and Why Does It Matter? // Independent. May 9, 2018. URL: https://www.independent. co.uk/news/world/middle-east/iran-nuclear-deal-whytrump-us-withdraw-effect-europe-rouhani-latest-a8343496. html (дата обращения: 01.08.2019).

7. Кортунов А.В. Чего хочет добиться Вашингтон от Тегерана? URL: https://russiancouncil.ru/analytics-andcomments/analytics/chego-khochet-dobitsya-vashington-ottegerana/ (дата обращения: 01.08.2019).

8. Мамедова Н.М., Дунаева Е.В., Федорова И.Е. Иран после президентских выборов // Свободная мысль. 2013. №5.

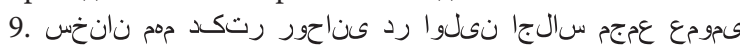
URL: http://www. president.ir/fa/71823 (дата обращения: 19.10.2018).

10. Obama Holds Historic Phone Call with Rouhani and Hints at End to Sanctions. URL: https://www.theguardian. com/world/2013/sep/27/obama-phone-call-iranianpresident-rouhani (дата обращения: 15.02.2019).

11. Федорова И.Е. США, Евросоюз и Исламская Республика Иран после принятия Совместного всеобъемлющего плана действий // Труды Института востоковедения РАН. 2017. № 5.

12. President Donald J. Trump's New Strategy on Iran. URL: https://www.whitehouse.gov/briefings-statements/presidentdonald-j-trumps-new-strategy-iran/ (дата обращения: 13.02.2019).

13. Iran President Hassan Rouhani to Speak on Trump's Decision Not to Certify Nuclear Deal. URL: https://www. youtube.com/watch?v=WKGT9ZFox7w (дата обращения: 13.02.2019).
14. Румянцев В.П. На перепутье: политика США в отношении Ирана на первом этапе «Белой революции» (1961-1963 гг.) // Американский ежегодник. 2015. М., 2016.

15. Trump to Approve Iran Nuclear Deal for Last Time URL: https://www.bbc.com/news/world-us-canada-42670577 (дата обращения: 09.05.2019).

16. Ceasing U.S. Participation in the JCPOA and Taking Additional Action to Counter Iran's Malign Influence and Deny Iran All Paths to a Nuclear Weapon URL: https://www.whitehouse. gov/presidential-actions/ceasing-u-s-participation-jcpoa-takingadditional-action-counter-irans-malign-influence-deny-iranpaths-nuclear-weapon/ (дата обращения: 13.02.2019).

17. Румянцев В.П. Между реформами и репрессиями: эволюция американо-иранских отношений в XIX - первой половине XX вв. // Вестник Томского государственного университета. 2015. № 397.

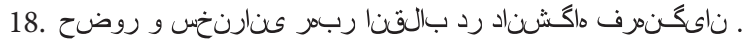
URL: http://farsi.khamenei.ir/news-content?id=39523 (дата обращения: 01.08.2019).

19. Pleitgen F. In Iran, Hardliners Are Burning the Deal and the American Flag. URL: https:/edition.cnn. com/2018/05/09/middleeast/iran-reacts-nuclear-deal-intl/ index.html (дата обращения: 01.08.2019).

20. Iranian Officials' Reactions to US' Withdrawal from JCPOA. URL: https://en.isna.ir/news/97021910636/Iranianofficials-reactions-to-US-withdrawal-from-JCPOA (дата обращения: 01.08.2019).

21. The Washington Post. May 9. 2018.

22. Mousavian S.H. How Iran Sees Its Standoff with the United States. URL: https://www.foreignaffairs.com/articles/ iran/2019-07-12/how-iran-sees-its-standoff-united-states (дата обращения: 01.08.2019).

23. Вачедин Д. В Иране прошли антиправительственные протесты // Информационное агенство Deutsche Welle. 5 августа 2018 г. URL: https://www.dw.com/ru/в-иранепрошли-антиправительственные-протесты/а-44957321 (дата обращения: 02.08.2019).

24. Лариджани: Трамп слишком мал, чтобы поставить на колени Иран. URL: http://parstoday.com/ru/news/ iran-i95435 (дата обращения: 30.07.2019).

25. Гнев Помпео на антиамериканскую и антиизраильскую позицию президента Ирана. URL: http://parstoday. com/ru/news/iran-i96125 (дата обращения: 01.08.2019).

26. Twitter of President of the Islamic Republic of Iran Hassan Rouhani. 08:27 - September 4, 2013. URL: https:// twitter.com/HassanRouhani/status/375278962718412800/ photo/1 (дата обращения: 30.07.2019).

27. США объявили иранский Корпус стражей исламской революции террористической организацией // Русская служба BBC. 2019. 8 апреля. URL: https:// www.bbc.com/russian/news-47859074 (дата обращения: 01.08.2019). 